\title{
DISTRIBUSI SPASIAL DENSITAS CAKRAM BERUKURAN SAMA DALAM PEMODELAN PEMBENTUKAN ASTEROID
}

\author{
Sparisoma Viridi ${ }^{1, a)}$, Budi Dermawan ${ }^{2, b)}$ \\ ${ }^{1}$ Prodi Fisika, Fakultas Matematika dan Ilmu Pengetahuan Alam Institut Teknologi Bandung, Jalan Ganesha \\ 10, Bandung 40132, Indonesia \\ ${ }_{2}^{2}$ Prodi Astronomi, Fakultas Matematika dan Ilmu Pengetahuan Alam Institut Teknologi Bandung, Jalan \\ Ganesha 10, Bandung 40132, Indonesia
}

Email: ${ }^{a)}$ dudung@fi.itb.ac.id, b)budider@as.itb.ac.id

\begin{abstract}
Abstrak
Sejumlah partikel dua-dimensi berbentuk cakram yang hanya berinteraksi melalui gaya gravitasi dan gaya normal disimulasikan. Diasumsikan terdapat dua nilai densitas partikel (berukuran sama tetapi bermassa berbeda). Simulasi dijalankan sampai susunan partikel relatif tidak lagi banyak berubah. Diperoleh bahwa densitas bervariasi secara radial, semakin besar ke dalam, dan hampir isotropik secara angular pada keadaan akhir. Telah disimulasikan $\mathrm{N}=64$ partikel dengan rasio massa $\mathrm{mA} / \mathrm{mB}=0.25$ selama waktu simulasi $944 \mathrm{~s}$.
\end{abstract}

Kata-kata kunci: pembentukan asteroid, material granular, distribusi densitas, campuran biner.

\begin{abstract}
Several two-dimension particles in the form of a disk, which only interact through gravitational force and normal force, are simulated. Assumed that there are only two values of particle density (same diameter but different mass). Simulation are conducted until particles position are slightly constant. It is obtained that density is varied radially, decreasing with an increase of radial position, and nearly isotropic angularly in final condition. It has been simulated $\mathrm{N}=64$ particles with mass ratio $\mathrm{mA} / \mathrm{mB}=$ 0.25 for $944 \mathrm{~s}$ simulation time.
\end{abstract}

Keywords: asteroid forming, granular material, density distribution, binary mixture.

\section{PENDAHULUAN}

Porositas dan juga densitas asteroid yang amat bervariasi [1], membuatnya menarik untuk dipelajari, terutama setelah adanya hasil observasi dengan resolusi tinggi mengenai permukaanya [2]. Untuk mempelajarinya lebih lanjut, partikel berbentuk cakram yang bertumbukan tak-elastik telah digunakan dalam model dua-dimensi untuk pembentukan asteroid [3], yang menunjukkan terjadinya kompaksi atau peningkatan kontaktopi [4], selama sistem berevolusi ke keadaan stabilnya. Dalam tulisan ini akan dibahas bagaimana evolusi densitas sistem. 


\section{METODE PENELITIAN}

Pembentukan asteroid dimodelkan dalam 2-dimensi dengan menggunakan $N$ buah partikel berbentuk cakram berdiameter $D_{i}$ dan bermassa $m_{i}$, yang memiliki posisi awal $\vec{r}_{i}(0)$ dan kecepatan awal $\vec{v}_{i}(0)$, dengan $i=1 . . N^{2}$. Posisi pusat sistem partikel $\vec{r}_{c}=x_{c} \hat{x}+y_{c} \hat{y}$ dan

$$
L=\beta \max \left(\left\{D_{i}\right\}_{i=1}^{N}\right)
$$

digunakan untuk mementukan posisi awal partikel $i$

$$
x_{i}(0)=\left[x_{c}-\frac{L}{2}(N-1)\right]+\left((i-1)-N\left[\frac{(i-1)}{N}\right]\right) L
$$

dan

$$
y_{i}(0)=\left[y_{c}-\frac{L}{2}(N-1)\right]+\left\lfloor\frac{(i-1)}{N}\right\rfloor L
$$

sehingga dapat diperoleh $\vec{r}_{i}(0)=x_{i}(0) \hat{x}+y_{i}(0) \hat{y}$. Notasi $\lfloor x\rfloor$ menyatakan fungsi floor $(x)$, dengan salah satu definisinya adalah [5]

$$
\lfloor x\rfloor=\max \{m \in \mathbb{Z} \mid m \leq x\},
$$

dengan $\mathbb{Z}$ adalah himpunan bilangan bulat dan

$$
\max (a, b)= \begin{cases}a, & a \geq b \\ b, & a<b\end{cases}
$$

yang untuk lebih banyak argumennya akan memenuhi hubungan rekursif

$$
\max (a, b, c)=\max (\max (a, b), c)
$$

untuk digunakan dalam Persamaan (1) dan (4). Hasil penerapan Persamaan (2) dan (3) diberikan dalam Gambar 1.



GAMBAR 1. Ilustrasi posisi awal partikel-partikel untuk $\mathrm{N}=2, \mathrm{D}=0.8, \beta=1.25$ dan $\vec{r}_{c}=(0,0)$.

Selanjutnya adalah membahas gaya-gaya interaksi antar partikel yang dalam hal ini hanya dua jenis gaya interaksi yang diperhitungkan, yaitu gaya gravitasi dan gaya normal. Gaya pertama merupakan gaya tarik-menarik antar partikel dan gaya kedua menggambarkan tumbukan antar partikel yang mencegah dua buah partikel menempati posisi yang sama dalam waktu yang sama. 
Gaya gravitasi bersifat rentang-jauh yang selalu ada, sendangkan gaya kedua bersifat rentang-dekat yang hanya bernilai saat dua buah partikel beririsan. Untuk menghitung kedua gaya tersebut perlu didefinisikan vektor posisi relatif $\vec{r}_{i j}$ dan vektor kecepatan relatif $\vec{v}_{i j}$ serta vektor satuannya masingmasing, yaitu

$$
\begin{gathered}
\vec{r}_{i j}=\vec{r}_{i}-\vec{r}_{j}, \\
r_{i j}=\left|\vec{r}_{i j}\right|=\sqrt{\vec{r}_{i j} \cdot \vec{r}_{i j}}, \\
\hat{r}_{i j}=\frac{\vec{r}_{i j}}{r_{i j}},
\end{gathered}
$$

dan dengan cara yang mirip untuk mendapatkan yang terkait dengan vektor kecepatan. Gaya gravitasi dinyatakan melalui

$$
\vec{G}_{i j}=-k_{G} \frac{m_{i} m_{j}}{r_{i j}^{2}} \hat{r}_{i j},
$$

yang menggambarkan gaya gravitasi yang dialami oleh mass $m_{i}$ pada posisi $\vec{r}_{i}$ akibat adanya massa $m_{j}$ pada posisi $\vec{r}_{j}$. Irisan antara cakram $i$ dan cakram $j$ dapat didefinisikan sebagai

$$
\xi_{i j}=\max \left[0, \frac{1}{2}\left(D_{i}+D_{j}\right)-r_{i j}\right],
$$

di mana masing-masing cakram berdiameter $D_{i}$ dan $D_{j}$. Dengan menggunakan Persamaan (11) gaya normal dapat dinyatakan dalam bentuk

$$
\vec{N}_{i j}=k_{R} \xi_{i j} \hat{r}_{i j}-k_{V} \operatorname{sign}\left(\xi_{i j}\right) \vec{v}_{i j},
$$

dengan fungsi $\operatorname{sign}(x)$ berarti

$$
\operatorname{sign}(x)= \begin{cases}0, & x=0, \\ \frac{x}{|x|} & x \neq 0 .\end{cases}
$$

Dari Persamaan (11) akan dapat diperoleh bahwa kasus ini Persamaan (13) hanya dapat bernilai 0 atau 1 . Terdapat tiga konstanta yang harus diberikan nilainya, yaitu $k_{G}, k_{R}$, dan $k_{V}$. Konstanta pertama terkait dengan gaya graviasi dan dua konstanta terakhir terkait dengan gaya normal. Sifat rentangdekat dari gaya kedua disyaratkan oleh Persamaan (11).

Gaya total yang dialami oleh partikel $i$ akibat $N-1$ partikel lainnya diperoleh melalui

$$
\vec{F}_{i}=\sum_{\substack{j=1 \\ j \neq i}}^{N}\left(\vec{G}_{i j}+\vec{N}_{i j}\right),
$$

yang kemudian dengan Hukum Newton II akan memberikan

$$
\vec{a}_{i}=\frac{1}{m_{i}} \vec{F}_{i} .
$$

Kecepatan dan posisi partikel $i$ setiap saat $t$ dapat diperoleh secara teori melalui 


$$
\begin{aligned}
& \vec{v}_{i}(t)=\vec{v}_{i}(0)+\int_{0}^{t} \vec{a}_{i} d t, \\
& \vec{r}_{i}(t)=\vec{r}_{i}(0)+\int_{0}^{t} \vec{v}_{i} d t .
\end{aligned}
$$

Sayangnya Persamaan (16) dan (17) tidak dapat dengan mudah dihitung mengingat secara implisit $\vec{a}_{i}$ bergantung dari percepatan $N-1$ partikel lainnya pula. Untuk itu kedua persamaan ini akan diselesaikan secara numerik.

Dengan menggunakan algoritma Euler Persamaan (16) dan (17) dapat dituliskan menjadi

$$
\begin{aligned}
& \vec{v}_{i}(t+\Delta t) \approx \vec{v}_{i}(t)+\vec{a}_{i}(t) \Delta t, \\
& \vec{r}_{i}(t+\Delta t) \approx \vec{r}_{i}(t)+\vec{v}_{i}(t) \Delta t,
\end{aligned}
$$

dengan nilai $\Delta t$ yang kecil. Pada setiap saat $t$ kecepatan $\vec{v}_{i}(t)$ dan posisi $\vec{r}_{i}(t)$ dari partikel $i$ yang bermassa $m_{i}$ dan berdiameter $D_{i}$ dapat ditentukan.

Densitas spasial sistem partikel ditentukan dengan terlebih dahulu menentukan titik pusat sistem, yang dapat menggunakan rata-rata posisi partikel (average)

$$
\vec{r}_{\text {avg }}=\frac{1}{N} \sum_{i=1}^{N} m_{i} \vec{r}_{i},
$$

atau titik pusat massa sistem (center of mass)

$$
\vec{r}_{\mathrm{com}}=\frac{1}{M} \sum_{i=1}^{N} m_{i} \vec{r}_{i}
$$

dengan massa total sistem

$$
M=\sum_{i=1}^{N} m_{i}
$$

Atau dapat pula digambarkan himpungan lingkaran-lingkaran konsentris yang berpusat di $\vec{r}_{\text {con }}$ sedemikian rupa sehingga sistem partikel berada dalam ruang cincin-cincinnya. Bila terdapat $C$ buat lingkaran konsentris, maka jari-jari masing-masing lingkaran dapat dipilih bernilai

$$
R_{i}=\frac{i}{2} L, \quad i=1,2, . ., C
$$

Jumlah partikel dalam setiap lingkaran konsentris berjari-jari $R_{i}$ dinyatakan dengan melalui

$$
n_{i}=\sum_{j=1}^{N} \operatorname{sign}\left\{\max \left[0,\left(R_{i}+\frac{1}{2} D_{j}\right)-\left|\vec{r}_{\text {con }}-\vec{r}_{j}\right|\right]\right\},
$$

sehingga setiap cincin ke $i$ akan memiliki jumlah partikel

$$
\Delta n_{i}=n_{i}-n_{i-1}, \quad i=2,3, . ., C .
$$


Proses penghitungan dengan hanya menggunakan jumlah partikel dalam Persamaan (23) mengikuti prosedur untuk menghitung energi kontak sistem [6]. Dengan demikian densitas spasialnya dapat dinya-takan dengan

$$
\sigma_{i}=\frac{\Delta n_{i}}{\pi\left(R_{i}-R_{i-1}\right)}, \quad i=2,3, . ., C,
$$

yang baru memperhitungkan aspek dalam arah radial dan masih mengabaikan variasi dalam arah angular-nya.

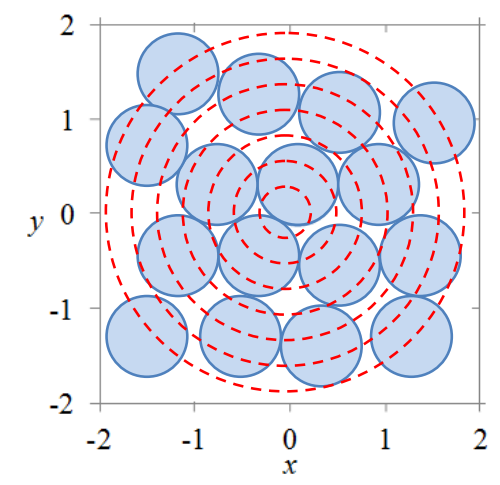

GAMBAR 2. Lingkaran-lingkaran konsentris (bergaris putus-putus berwarna merah) yang membagi ruang berupa cincincincin untuk menghitung densitas sistem partikel.

Nilai-nilai $\Delta n_{1}=2, \Delta n_{2}=4, \Delta n_{3}=6, \Delta n_{4}=7$, dan seterusnya dapat dilihat dalam Gambar 2 sebagai suatu ilustrasi.

\section{HASIL DAN PEMBAHASAN}

Dalam tulisan ini untuk sementara belum digunakan parameter dengan nilai-nilai sebenarnya, melainkan nilai-nilai sembarang yang dapat terlebih dahulu memberikan fenomena tertentu. Pada tahap selanjutnya akan digunakan nilai yang riil sehingg dapat dibandingkan dengan hasil pengukuran. Nilai-nilai parameter yang digunakan disajikan dalam Tabel 1 berikut.

Tabel 1. Parameter simulasi dan nilai-nilainya.

\begin{tabular}{ccc}
\hline No & Parameter & Nilai \\
\hline 1 & $\Delta t$ & 0.01 \\
2 & $k_{G}$ & 5 \\
3 & $k_{R}$ & $10^{5}$ \\
4 & $k_{V}$ & 1 \\
5 & $m_{\mathrm{A}}$ & 1 \\
6 & $m_{\mathrm{B}}$ & 4 \\
7 & $D$ & 1 \\
8 & $N^{2}$ & 64 \\
\hline
\end{tabular}

Dengan menggunakan parameter-parameter dalam tabel sebelumnya dapat diperoleh perubahan posisi partikel-partikel yang bergantung dari massa partikel. 

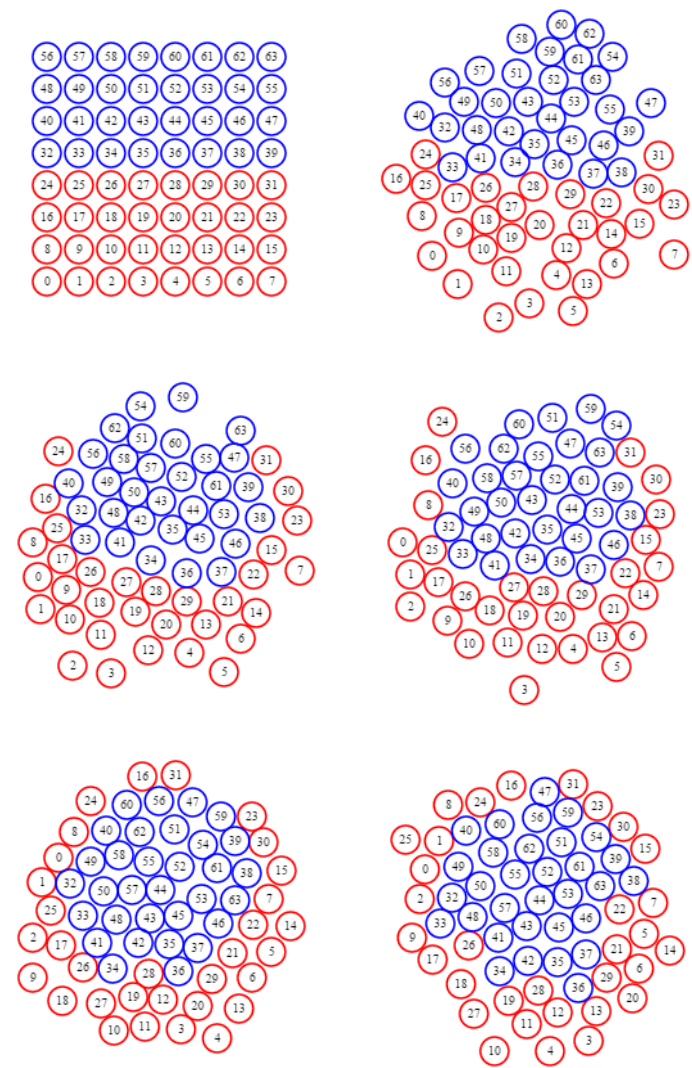

GAMBAR 3. Posisi partikel-partikel untuk beberapa waktu simulasi t: 0, 4, 20,40, 389, 944 s.

Partikel-partikel bermassa lebih kecil (merah) pada akhirnya akan berada pada posisi radial lebih besar, yang melingkupi partikel-partikel dengan massa lebih besar (biru) sebagaimana diberikan dalam Gambar 3. Untuk sementar hal ini diduga karena sistem ber-evolusi ke keadaan dengan energi potensial gravitasi yang lebih minimum.

Densitas spasial berubah sejalan dengan berubah-nya susunan partikel-partikel, sebagaimana diberikan dalam Gambar 4. Keadaan awal saat $t=0 \mathrm{~s}$ waktu simulasi tidak memberikan distribusi spasial densitas $\sigma$ yang bernilai maksimum dan keadaan akhir saat $\mathrm{t}=944 \mathrm{~s}$ waktu simulasi juga tidak memberikan sebaran $\sigma$ yang bernilai minimum. Hal ini dapat dijelaskan karena kondisi awal yang dipilih memang bukan merupakan keadaan riil yang mungkin terdapat di alam.

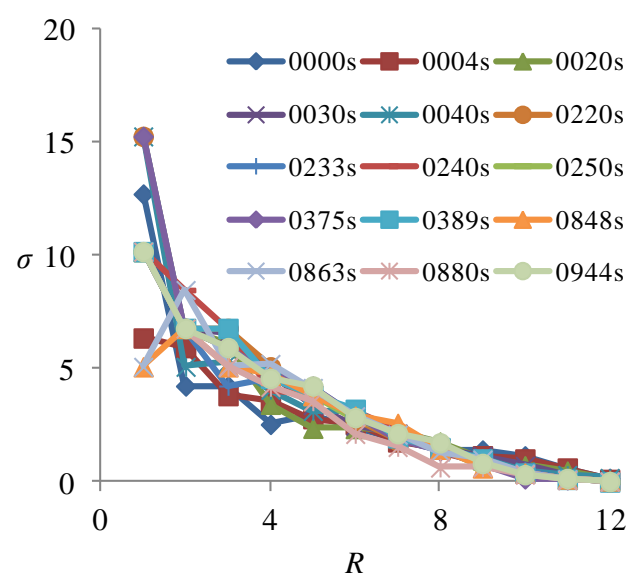

GAMBAR 4. Densitas spasial $\sigma$ sebagai fungsi dari jarak ke pusat sistem R untuk waktu simulasi antara $0 \mathrm{~s}$ dampai $944 \mathrm{~s}$. 
Perubahan jumlah partikel pada masing-masing area berbentuk cincin dengan jejari antara $R_{i}$ dan $R_{i}+\Delta R_{i}$ diberikan dalam Gambar 5. Saat $t=0$ s konfigu-rasi partikel ditetapkan seperti dalam Gambar 5(a). Selanjutnya partikel-partikel akan mengubah posisinya mengikuti gaya-gaya yang telah didefini-sikan sebelumnya dalam Persamaan (10) dan (12). Terlihat bahwa jumlah masing-masing jenis partikel, yang terletak antara $R_{i}$ dan $R_{i}+\Delta R_{i}$, yang semula sama untuk $t=0 \mathrm{~s}$, berangsur-angsur mulai berubah. Partikel-partikel yang lebih ringan $\left(m_{\mathrm{A}}\right.$, merah) bergeser ke daerah dengan jarak radial lebih besar, sedangkan partikel-partikel yang lebih berat $\left(m_{\mathrm{B}}\right.$, biru) bergeser ke daerah dengan jarak radial lebih kecil. Hal ini mirip dengan proses sentrifugal evaporasi dalam memisahkan isotop klorin [7], di mana gaya sentral yang berperan di sini adalah gaya gravitasi antar partikel.

Berubahnya energi potensial sistem $U$ terhadap pusatnya menarik untuk dibahas. Dengan menganggap terdapat massa total $M$ yang kira-kira setara dengan massa total sistem, dapat dihitung nilai $U$ menggunakan hasil dalam Gambar 5 sehingga dapat diperoleh hasil seperti diberikan dalam Gambar 6. Terlihat bahwa energi potensial untuk partikel yang lebih ringan $U_{1}$ cenderung menurun dengan bertambahnya waktu simulasi $t$, akan tetapi untuk partikel yang lebih berat energi potensialnya $U_{2}$ menaik dahulu baru kemudian menurun dengan nilai akhir mirip dengan nilai awal. Nilai $U_{2}$ ini mendominasi nilai energi potensial total sistem $U$ ketimbang nilai $U_{1}$. Dengan demikian prinsip energi potensial minimum dalam sistem ini belum sepenuhnya dapat terpenuhi.
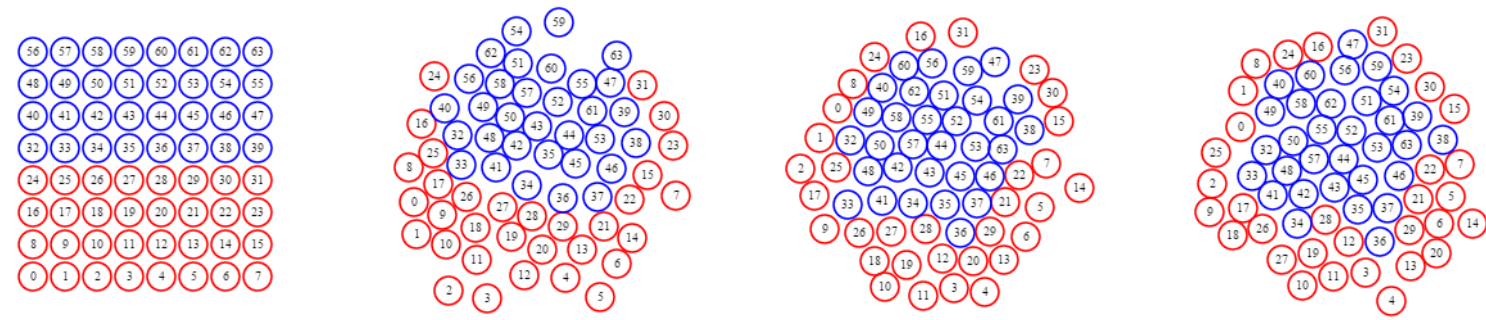

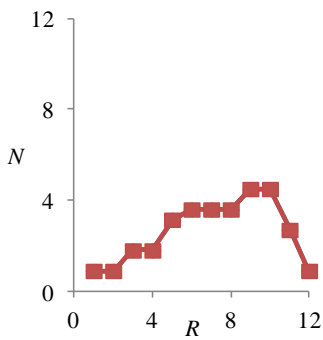

(a)

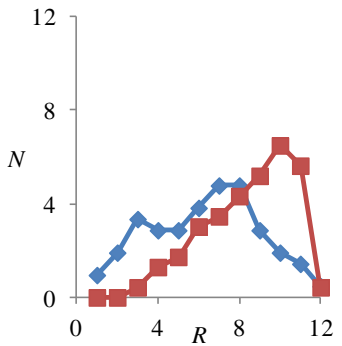

(b)

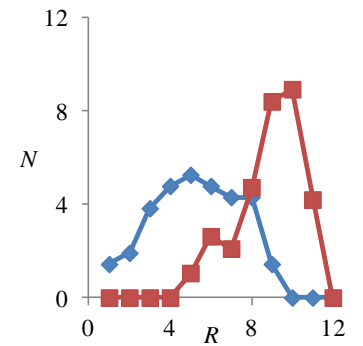

(c)

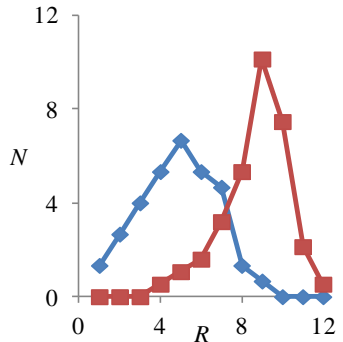

(d)

GAMBAR 5. Konfigurasi partikel (baris atas) dan jumlah kedua jenis partikel ( $m_{A}$ merah, $m_{B}$ biru) antara jarak $R_{i}$ dan $R_{i}+$ $\Delta \mathrm{R}_{\mathrm{i}}$ (baris bawah) untuk beberapa waktu simulasi t: (a) $0 \mathrm{~s}$, (b) $20 \mathrm{~s}$, (c) $220 \mathrm{~s}$, dan (d) $880 \mathrm{~s}$.

Hal ini dapat pula disebabkan perhitungan energi potensial gravitasi tidak menggunakan energi tiap partikel melainkan menggunakan posisi partikel yang telah didistribusikan dalam daerah-daerah berbentuk cincin dengan posisi radialnya terletak antara $R_{i}$ dan $R_{i}+\Delta R_{i}$.

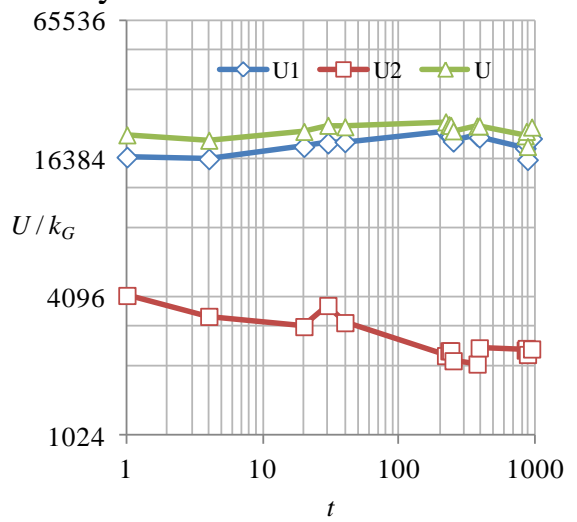

GAMBAR 6. Perubahan energi potensial untuk partikel yang lebih ringan $\left(\mathrm{U}_{1}\right)$, partikel yang lebih berat $\left(\mathrm{U}_{2}\right)$, dan total energi potensialnya $(\mathrm{U})$. 
Penentuan pusat koordinat sistem untuk menghitung $U$ juga berperan dalam menentukan evolusi dari $U$. Dalam penelitian berikutnya hal-hal ini akan ditelaah lebih lanjut sehingga sifat-sifat sistem yang diperoleh tidak lagi bergantung pada parameter-parameter tersebut.

\section{SIMPULAN}

Simulasi 64 buah partikel berdiameter sama dengan rasio massa 0.25 telah dilakukan dan telah dapat diperoleh variasi densitas secara radial, dengan semakin renggang dengan bertambahnya jarak dari pusat sistem. Teramati evolusi perubahan komposisi jumlah partikel, di mana partikel yang lebih berat cenderung menuju pusat sedangkan partikel yang lebih ringan sebaliknya. Prinsip energi potensial minimum terlihat hanya berlaku pada partikel yang lebih ringan.

\section{UCAPAN TERIMAKASIH}

Terima kasih pada Program Riset Institut Teknologi Bandung (Riset ITB) tahun 2017 dengan nomor 107x/I1.C01/PL/2017 yang mendukung penelitian ini.

\section{REFERENSI}

[1] E. Asphaug, "Growth and Evolution of Asteroids", Ann Annu. Rev. Earth Planet. Sci., vol. 37, pp. 413-448, Jan. 2009.

[2] H. Miyamoto, H. Yano, D. J. Scheeres, S. Abe, O. Barnouin-Jha, A. F. Cheng, H. Demura, R. W. Gaskell, N. Hirata, M. Ishiguro, T. Michikami, A. M. Nakamura, R. Nakamura, J. Saito, S. Sasaki, "Regolith Migration and Sorting on Asteroid Itokawa", Science vol. 316, pp. 1011-1014, 2007.

[3] S. Viridi, B. Dermawan, "Tumbukan Tak-Elastik Partikel sebagai Model Terbentuknya Asteroid", Spektra: J. Fis. Aplikasinya vol. 2, pp. 53-60, Mar. 2017.

[4] S. Viridi, B. Dermawan, "Cluster compaction of two-dimension spherical particles binary mixture as model of forming process of an asteroid", J. Physics: Conf. Ser. vol. 771, p. 012028, 2016.

[5] Wikipedia-Autoren, "Abrundungsfunktion und Aufrundungsfunktion", Wikipedia, Die freie Enzyklopädie, 18 Jan 2017 16:12 UTC, oid(de):161763853 [20170505 2333].

[6] S. Viridi, S. N. Khotimah, Novitrian, Widayani, "Fluctuation Theorem Application on 2-D Granular Materials Configurations", Adv. Mat. Res. vol. 1123, pp. 12-15, 2015.

[7] J. W. Beams and C. Skarstrom, "The Concentration of Isotopes by the Evaporative Centrifuge Method", Phys. Rev. vol. 56, pp. 266-272, 1939. 